\title{
Liver X receptors as potential targets for cancer therapeutics (Review)
}

\author{
XIAOLI JU ${ }^{1}$, PAN HUANG ${ }^{1}$, MIAO CHEN ${ }^{1,2}$ and QIANG WANG ${ }^{3}$ \\ ${ }^{1}$ Department of Pathology, School of Medicine; ${ }^{2}$ Department of Pathology, The Affiliated People's Hospital; \\ ${ }^{3}$ Institute of Life Sciences, Jiangsu University, Zhenjiang, Jiangsu 212013, P.R. China
}

Received November 9, 2016; Accepted September 7, 2017

DOI: 10.3892/ol.2017.7259

\begin{abstract}
Liver X receptors (LXRs) are important members of the nuclear receptor family that were originally determined to function in cholesterol transport and the regulation of immune responses. Synthetic LXR ligands have been developed to treat various diseases including diabetes, Alzheimer's disease and atherosclerosis. Previous studies have suggested that LXRs are also involved in numerous types of cancer and are therefore potential targets for cancer therapeutics. The present review summarizes LXR ligands and their mechanisms of action, the effects of LXRs in different types of cancer and their potential applications in clinical treatment. Together, the studies discussed in the present review indicate that LXRs may be potential targets for cancer therapeutics.
\end{abstract}

\section{Contents}

1. Introduction

2. LXR ligands and mechanism of action

3. Effects of LXRs in different types of cancer

4. LXRs and tumor immunity

5. Conclusion

\section{Introduction}

The nuclear receptor (NR) superfamily consists of important ligand-inducible transcription factors that are involved in various physiological processes, including cell differentiation, embryonic development and metabolism $(1,2)$. NR signaling serves important roles in a number of diseases including cancer,

Correspondence to: Dr Qiang Wang, Institute of Life Sciences, Jiangsu University, 301 Xuefu Road, Zhenjiang, Jiangsu 212013, P.R. China

E-mail: wangqiang@ujs.edu.cn

Key words: liver $\mathrm{X}$ receptors, cancer, cancer therapeutics, clinical application diabetes and metabolic diseases (1-3). Liver X receptors (LXRs) are important members of the NR family that were originally identified as major sensors of dietary cholesterol (4). Two LXRs, LXR $\alpha(\mathrm{NR} 1 \mathrm{H} 3)$ and LXR $\beta$ (NR1H2), were initially identified in a human liver cDNA library screen as orphan receptors (5-7). LXRs are involved in cholesterol synthesis and transport, glucose homeostasis, and the modulation of inflammatory and immune responses (8-10). LXRs exhibit the typical structure of the NR superfamily. $\mathrm{LXR} \alpha$ and $\mathrm{LXR} \beta$ harbor four distinct domains: i) An N-terminal activation domain (AF-1); ii) a DNA-binding domain with two zinc fingers; iii) a hinge domain that binds co-repressors in the absence of ligand; and iv) a C-terminal domain that contains a hydrophobic ligand-binding domain and a transactivation domain $(11,12)$.

\section{LXR ligands and mechanism of action}

LXRs were initially identified as orphan receptors. However, later studies identified oxysterols, or oxidized metabolites of cholesterol, as the endogenous ligands of LXR $\alpha$ and LXR $\beta(13,14)$. Furthermore, 22(R)-hydroxycholesterol, $20(S)$-hydroxycholesterol, 24-hydroxycholesterol, $7 \alpha$-hydroxycholesterol and 27-hydroxycholesterol also activate LXRs $(13,15)$. Additionally, microbial and plant-derived sitosterol, sitostanol and acanthoic acid from Rollinia function as LXR agonists $(16,17)$. Since the initial identification of endogenous LXR ligands, synthetic ligands have been developed by numerous pharmaceutical companies. T0901317 was the first synthetic LXR agonist to be developed, and is the most widely used in basic research. However, this compound may also activate two other NRs: Farnesoid X receptor and pregnane $\mathrm{X}$ receptor $(18,19)$. A more selective synthetic agonist, GW3965, was identified in a screen of GlaxoSmithKline (Brentford, UK) compounds (20). However, neither of these agonists is used therapeutically owing to their temporary hypertriglyceridemic effects $(20,21)$. More recently, promising synthetic ligands including 22(E)-ergost-22-ene-1 $\alpha, 2 \beta$-diol and $N, N$-dimethyl$3 \beta$-hydroxycholenamide have been developed with fewer side effects and greater potential for use in clinical testing $(22,23)$.

In the absence of a ligand, LXRs form obligate heterodimers with the retinoid $X$ receptor. These heterodimers bind to target gene promoters harboring the conserved LXR-response element, which consists of two direct repeats of AGGTCA separated by four nucleotides or one nucleotide. 
Table I. Effects of LXR in different types of cancer.

\begin{tabular}{llll}
\hline Ligand & Tumor type & & Molecular mechanism \\
\hline LXR $\alpha$ and LXR $\beta$ & Colon & Wnt signaling pathway, cell cycle arrest and pyroptosis & $(25-29)$ \\
LXR $\alpha$ and LXR $\beta$ & Prostate & AKT survival signaling, MAPK transduction pathways & $(29-34)$ \\
LXR $\alpha$ and LXR $\beta$ & Breast & EST, E2F family members & $(35-39)$ \\
LXR $\beta$ & Pancreatic & Inhibits cell proliferation, cell cycle arrest & $(40,41)$
\end{tabular}

LXR, liver X receptor; AKT, protein kinase B; MAPK, mitogen-activated protein kinase; EST, estrogen sulfotransferase; E2F, E2 factor.

A

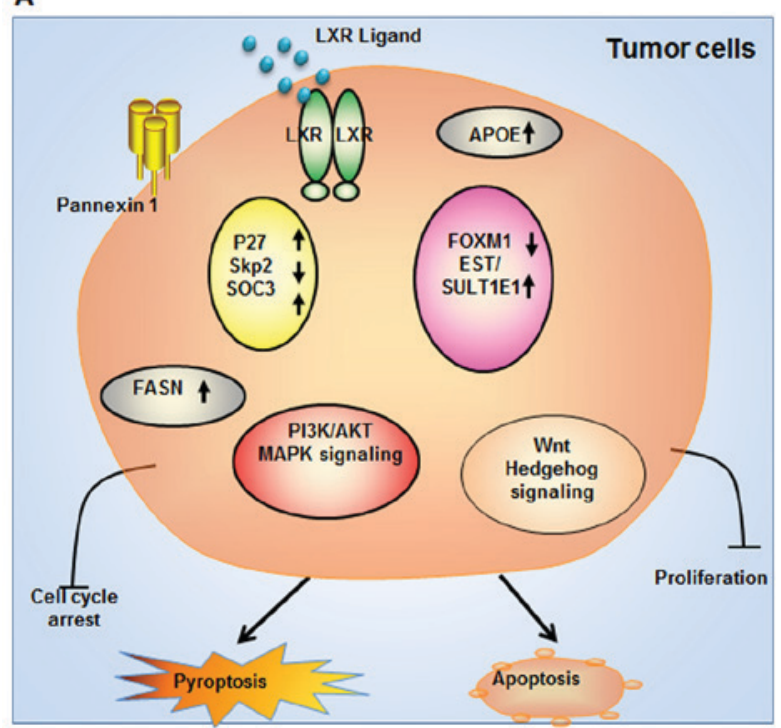

.

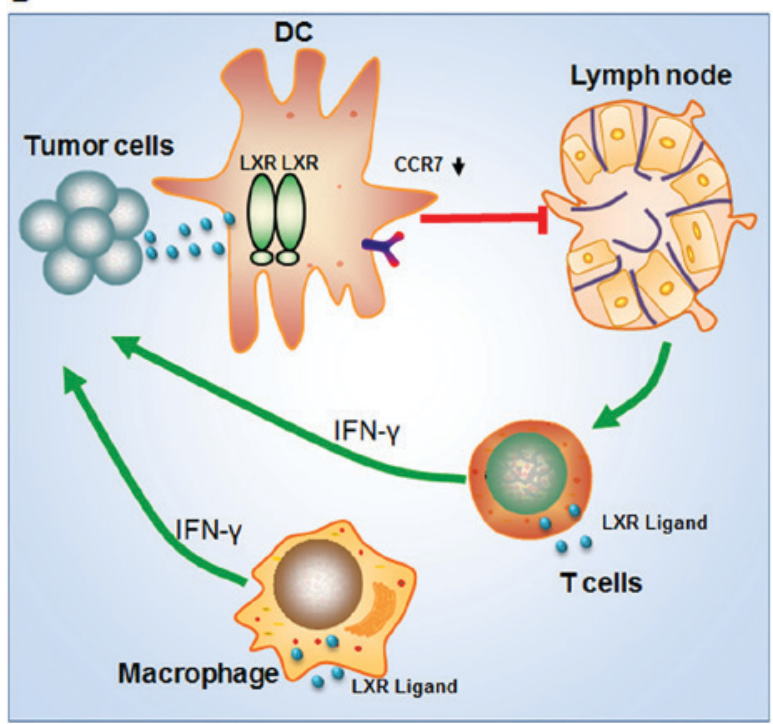

Figure 1. (A and B) Model of LXR agonist activation in various types of cancer and tumor immunity. LXR, liver X receptor; APOE, apolipoprotein E; p27, cyclin-dependent kinase inhibitor 1B; Skp2, S-phase kinase-associated protein 2; SOC3, suppressor of cytokine signaling 3; FOXM1, forkhead box M1; EST, estrogen sulfotransferase; SULT1E1, sulfotransferase family 1E member 1; FASN, fatty acid synthase; PI3K, phosphoinositide 3-kinase; MAPK, mitogen-activated protein kinase; IFN- $\gamma$, interferon- $\gamma$; AKT, protein kinase B; CCR7, C-C chemokine receptor type 7; DC, dendritic cell.

The heterodimer forms a complex with NR co-repressor (NCoR) to block transcription (24). Upon ligand binding to the heterodimer, NCoR is released from the complex and co-activators are recruited, leading to chromatin remodeling and target gene transcription (12).

\section{Effects of LXRs in different types of cancer}

LXRs and colon cancer. LXR agonists suppress colon carcinogenesis by several mechanisms (Fig. 1A). Uno et al (25) demonstrated that LXR agonists block the activation of Wnt signaling by suppressing the transactivation activity of $\beta$-catenin. In HCT116 cells, LXR agonists decrease the mRNA expression of $\beta$-catenin target genes, including MYC proto-oncogene, matrix metalloproteinase 7 and bone morphogenetic protein 4. Notably, in colon cancer cells, LXR agonists inhibit endogenous $\beta$-catenin activity and cell proliferation without inducing apoptosis. Consistent with this result, LXR ligands induce pyroptosis, rather than apoptosis, in human and murine colon cancer cells. Pyroptosis is dependent on caspase-1 activation. More importantly, LXRs also serve non-genomic roles due to the differential cytoplasmic localization of LXR $\beta$. LXR $\beta$ is predominantly located in the cytoplasm of colon cancer cells and induces pyroptosis when bound by ligand $(26,27)$. Previously, a study revealed that LXR activation leads to cell cycle arrest in colon cancer cell lines. Furthermore, proliferation markers in the colon are significantly increased in LXR $\alpha \beta(-/-)$ mice compared with wild-type mice (28). Together, inhibition of the Wnt signaling pathway and cell cycle arrest serve important roles during LXR ligand-dependent inhibition of colon cancer cell proliferation (Table I). Ligand-mediated activation of LXR may suppress the growth of colon cancer (29).

LXRs and prostate cancer. Liao and colleagues were the first to report that the LXR agonist T0901317 inhibits the proliferation of human prostate LNCaP cells (30). T0901317 decreases the number of cells in S-phase and increases the expression of the cyclindependent kinase inhibitor p27 (Fig. 1A). LXR $\alpha$ expression levels are associated with the sensitivity to T0901317-mediated growth inhibition. Additionally, T0901317-treated nude mice exhibited decreased growth of xenograft LNCaP tumors. Additional studies revealed that protein kinase B survival signaling is downregulated following T0901317 treatment, and that T0901317 induces the apoptosis of LNCaP cells in a lipid raft-dependent manner in vitro 
and in vivo (31). LXR agonists were demonstrated to inhibit cell proliferation and induce G1/S arrest through lipogenic activity (32). Furthermore, a prior study identified cross-talk between the androgen receptor and LXR, and determined that this interaction influences cellular cholesterol levels (33). The suppressor of cytokine signaling 3 pathway is also involved in LXR agonist-mediated prostate carcinogenesis (34) (Table I). Taken together, these results suggest that LXRs may be promising pharmacological targets for the treatment of prostate cancer.

LXRs and breast cancer. Estrogen metabolism serves an important role in breast cancer and LXR controls estrogen homeostasis (35) (Table I). Estrogen sulfotransferase (EST) is a transcriptional target of LXR. In in vitro and in vivo breast cancer models, LXR inhibits estrogen-dependent cancer cell proliferation by regulating the hepatic expression of EST. These results suggest that LXR inhibits breast cancer growth through a novel mechanism involving the regulation of estrogen homeostasis (35). However, LXR agonists were demonstrated to decrease the proliferation of several breast cancer cell lines independent of lipid biosynthesis (36). LXR agonists decrease the proliferation of cells in S-phase and induce $G_{1}$ arrest and apoptosis in MCF-7 cells (37,38). Microarray analysis of gene expression revealed that LXR ligands target a set of common responsive genes, including those regulated by E2 factor family members (39).

LXRs and pancreatic cancer. Pancreatic cancer is one of the most fatal types of cancer; the 5-year survival rate of patients with pancreatic ductal adenocarcinoma (PDAC) is only 5\%. LXR agonists inhibit cell proliferation, cell-cycle arrest and colony formation in pancreatic cancer cell lines and regulate multiple gene networks involved in cell-cycle arrest and growth factor signaling (40) (Fig. 1A). However, LXR agonists do not induce apoptosis in PDAC cells (40). Further study is required to clarify the types of cell death induced by LXR agonists. Notably, a prior study revealed that the LXR agonist 22(R)-dihydroxycholesterol (Oxy16) inhibits pancreatic cancer cell-induced paracrine Hedgehog signaling (Table I). However, this inhibition is independent of LXR activation (41).

\section{LXRs and tumor immunity}

It has been reported that LXRs are involved in innate and adaptive immune responses in various diseases $(42,43)$. LXR $\alpha \beta(-/-)$ mice are highly susceptible to intracellular bacterial infection, suggesting that LXR-dependent gene expression serves an important role in innate immunity (42). A-Gonzalez et al (44) revealed that LXR signaling promotes apoptotic cell clearance by macrophages and the maintenance of immune tolerance. LXR signaling is also involved in the regulation of other types of immune cell (Fig. 1B). LXR activation inhibits lymphocyte proliferation, and loss of LXR expression confers a proliferative advantage on lymphocytes (45). LXR agonists induce interferon- $\gamma$ expression in macrophages and T-cells, and increase the survival rate and the tumor-free population of mice inoculated with tumor cells $(46,47)$. However, further studies are required to clarify whether these effects are conserved in other model systems. In Th17 cells, ectopic expression of
LXR negatively regulates differentiation, whereas loss of LXR expression promotes differentiation (48). The role of LXR in dendritic cells (DCs) and tumor immunity is controversial. Villablanca et al (49) reported that LXR ligands released from tumor cells inhibit C-C chemokine receptor type 7 (CCR7) expression on maturing DCs. In mice, abrogating LXR agonist release from tumor cells controls tumor growth by recovering DC migration to the tumor area (49). However, another study revealed that treatment with LXR agonists increased CCR7 mRNA expression in an immature DC line (50). Additional investigations are required to determine the underlying molecular mechanism of the potentially opposing roles of LXR.

The antitumor effects of LXR agonists are also evident in the tumor microenvironment. LXR agonists impair the compartmentation of vascular endothelial growth factor receptor-2 in lipid rafts and decrease tumor growth by inhibiting angiogenesis (51). Furthermore, LXR $\beta$ agonist treatment induces apolipoprotein $\mathrm{E}$ secretion by stromal and tumor cells and blocks tumor growth, angiogenesis and metastasis (52). However, further studies are required in order to investigate whether other types of cell in the tumor microenvironment are influenced by LXR $\beta$ agonists.

\section{Conclusion}

LXR ligands have been developed to treat various diseases, including diabetes, Alzheimer's disease, atherosclerosis and cancer. In spite of progress, a number of fundamental questions remain with respect to cancer therapeutics. A number of natural and synthetic LXR ligands have been identified. T0901317 and GW3965 are the most widely used agonists for mechanistic and functional studies of LXR activity. However, T0901317 has been reported to increase triacylglycerol levels in the plasma and liver and was therefore suggested to be a poor candidate for clinical application (29). New synthetic agonists, including LXR-623, were developed to minimize the side effects on plasma triacylglycerol levels for clinical testing. The development of novel agonists, particularly for cancer treatment, may accelerate basic and clinical applications. The expression profiles of the two LXRs in clinical samples are unknown, and whether these expression profiles are associated with disease subtype, pathological parameters or disease outcomes requires clarification. Endogenous ligands in tumor and stromal cells must also be identified. Taken together, these results suggest that LXRs may be potential targets for cancer therapeutics.

\section{Acknowledgements}

The present review was supported by the National Natural Science Foundation of China (grant nos. 81502088, 81502621 and 81300287), Special Postdoctoral Science Foundation of China (no. 2017T100335), the Natural Science Foundation of Jiangsu Province (grant no. BK20140539) and the Start-Up Research Funding of Jiangsu University for Distinguished Scholars (grant nos. 14JDG065 and 15JDG021).

\section{References}

1. Gronemeyer H, Gustafsson JA and Laudet V: Principles for modulation of the nuclear receptor superfamily. Nat Rev Drug Discov 3: 950-964, 2004. 
2. Nuclear Receptors Nomenclature Committee: A unified nomenclature system for the nuclear receptor superfamily. Cell 97: 161-163, 1999.

3. Evans RM and Mangelsdorf DJ: Nuclear receptors, RXR, and the big bang. Cell 157: 255-266, 2014.

4. Peet DJ, Turley SD, Ma W, Janowski BA, Lobaccaro JM, Hammer RE and Mangelsdorf DJ: Cholesterol and bile acid metabolism are impaired in mice lacking the nuclear oxysterol receptor LXR alpha. Cell 93: 693-704, 1998.

5. Apfel R, Benbrook D, Lernhardt E, Ortiz MA, Salbert G and Pfahl M: A novel orphan receptor specific for a subset of thyroid hormone-responsive elements and its interaction with the retinoid/thyroid hormone receptor subfamily. Mol Cell Biol 14 7025-7035, 1994.

6. Willy PJ, Umesono K, Ong ES, Evans RM, Heyman RA and Mangelsdorf DJ: LXR, a nuclear receptor that defines a distinct retinoid response pathway. Genes Dev 9: 1033-1045, 1995.

7. Shinar DM, Endo N, Rutledge SJ, Vogel R, Rodan GA and Schmidt A: NER, a new member of the gene family encoding the human steroid hormone nuclear receptor. Gene 147: 273-276, 1994.

8. Wang Y, Rogers PM, Stayrook KR, Su C, Varga G, Shen Q, Nagpal S and Burris TP: The selective Alzheimer's disease indicator-1 gene (Seladin-1/DHCR24) is a liver X receptor target gene. Mol Pharmacol 74: 1716-1721, 2008.

9. Cha JY and Repa JJ: The liver X receptor (LXR) and hepatic lipogenesis. The carbohydrate-response element-binding protein is a target gene of LXR. J Biol Chem 282: 743-751, 2007.

10. Zelcer $\mathrm{N}$ and Tontonoz P: Liver $\mathrm{X}$ receptors as integrators of metabolic and inflammatory signaling. J Clin Invest 116 : 607-614, 2006.

11. Viennois E, Pommier AJ, Mouzat K, Oumeddour A, El Hajjaji FZ, Dufour J, Caira F, Volle DH, Baron S and Lobaccaro JM: Targeting liver X receptors in human health: Deadlock or promising trail? Expert Opin Ther Targets 15: 219-232, 2011.

12. Viennois E, Mouzat K, Dufour J, Morel L, Lobaccaro JM and Baron S: Selective liver X receptor modulators (SLiMs): What use in human health? Mol Cell Endocrinol 351: 129-141, 2012.

13. Janowski BA, Willy PJ, Devi TR, Falck JR and Mangelsdorf DJ: An oxysterol signalling pathway mediated by the nuclear receptor LXR alpha. Nature 383: 728-731, 1996.

14. Janowski BA, Grogan MJ, Jones SA, Wisely GB, Kliewer SA Corey EJ and Mangelsdorf DJ: Structural requirements of ligands for the oxysterol liver X receptors LXRalpha and LXRbeta. Proc Natl Acad Sci USA 96: 266-271, 1999.

15. Lehmann JM, Kliewer SA, Moore LB, Smith-Oliver TA, Oliver BB, Su JL, Sundseth SS, Winegar DA, Blanchard DE, Spencer TA and Willson TM: Activation of the nuclear receptor LXR by oxysterols defines a new hormone response pathway. J Biol Chem 272: 3137-3140, 1997.

16. Plat J, Nichols JA and Mensink RP: Plant sterols and stanols: Effects on mixed micellar composition and LXR (target gene) activation. J Lipid Res 46: 2468-2476, 2005.

17. Jayasuriya H, Herath KB, Ondeyka JG, Guan Z, Borris RP, Tiwari S, de Jong W, Chavez F, Moss J, Stevenson DW, et al: Diterpenoid, steroid, and triterpenoid agonists of liver X receptors from diversified terrestrial plants and marine sources. J Nat Prod 68: 1247-1252, 2005.

18. Schultz JR, Tu H, Luk A, Repa JJ, Medina JC, Li L, Schwendner S, Wang S, Thoolen M, Mangelsdorf DJ, et al: Role of LXRs in control of lipogenesis. Genes Dev 14: 2831-2838, 2000.

19. Houck KA, Borchert KM, Hepler CD, Thomas JS, Bramlett KS, Michael LF and Burris TP: T0901317 is a dual LXR/FXR agonist. Mol Genet Metab 83: 184-187, 2004.

20. Collins JL, Fivush AM, Watson MA, Galardi CM, Lewis MC Moore LB, Parks DJ, Wilson JG, Tippin TK, Binz JG, et al: Identification of a nonsteroidal liver $\mathrm{X}$ receptor agonist through parallel array synthesis of tertiary amines. J Med Chem 45: 1963-1966, 2002.

21. Joseph SB, McKilligin E, Pei L, Watson MA, Collins AR, Laffitte BA, Chen M, Noh G, Goodman J, Hagger GN, et al: Synthetic LXR ligand inhibits the development of atherosclerosis in mice. Proc Natl Acad Sci USA 99: 7604-7609, 2002.

22. Kaneko E, Matsuda M, Yamada Y, Tachibana Y, Shimomura I and Makishima M: Induction of intestinal ATP-binding cassette transporters by a phytosterol-derived liver X receptor agonist. J Biol Chem 278: 36091-36098, 2003.

23. Quinet EM, Savio DA, Halpern AR, Chen L, Miller CP and Nambi P: Gene-selective modulation by a synthetic oxysterol ligand of the liver X receptor. J Lipid Res 45: 1929-1942, 2004.
24. Hu X, Li S, Wu J, Xia C and Lala DS: Liver X receptors interact with corepressors to regulate gene expression. Mol Endocrinol 17: 1019-1026, 2003

25. Uno S, Endo K, Jeong Y, Kawana K, Miyachi H, Hashimoto Y and Makishima M: Suppression of beta-catenin signaling by liver X receptor ligands. Biochem Pharmacol 77: 186-195, 2009.

26. Derangère V, Chevriaux A, Courtaut $F$, Bruchard $M$, Berger $H$, Chalmin F, Causse SZ, Limagne E, Végran F, Ladoire S, et al: Liver $X$ receptor $\beta$ activation induces pyroptosis of human and murine colon cancer cells. Cell Death Differ 21: 1914-1924, 2014

27. Courtaut F, Derangère V, Chevriaux A, Ladoire $S$, Cotte AK Arnould L, Boidot R, Rialland M, Ghiringhelli F and Rébé C: Liver X receptor ligand cytotoxicity in colon cancer cells and not in normal colon epithelial cells depends on LXR $\beta$ subcellular localization. Oncotarget 6: 26651-26662,2015.

28. Vedin LL, Gustafsson JA and Steffensen KR: The oxysterol receptors $L X R \alpha$ and $L X R \beta$ suppress proliferation in the colon. Mol Carcinog 52: 835-844, 2013

29. Chuu CP: Modulation of liver X receptor signaling as a prevention and therapy for colon cancer. Med Hypotheses 76: 697-699, 2011.

30. Fukuchi J, Kokontis JM, Hiipakka RA, Chuu CP and Liao S: Antiproliferative effect of liver $\mathrm{X}$ receptor agonists on $\mathrm{LNCaP}$ human prostate cancer cells. Cancer Res 64: 7686-7689, 2004.

31. Pommier AJ, Alves G, Viennois E, Bernard S, Communal Y, Sion B, Marceau G, Damon C, Mouzat K, Caira F, et al: Liver $\mathrm{X}$ Receptor activation downregulates AKT survival signaling in lipid rafts and induces apoptosis of prostate cancer cells. Oncogene 29: 2712-2723, 2010.

32. Kim KH, Lee GY, Kim JI, Ham M, Won Lee J and Kim JB Inhibitory effect of LXR activation on cell proliferation and cell cycle progression through lipogenic activity. J Lipid Res 51: 3425-3433, 2010

33. Krycer JR and Brown AJ: Cross-talk between the androgen receptor and the liver $\mathrm{X}$ receptor: Implications for cholesterol homeostasis. J Biol Chem 286: 20637-20647, 2011.

34. Fu W, Yao J, Huang Y, Li Q, Li W, Chen Z, He F, Zhou Z and Yan J: LXR agonist regulates the carcinogenesis of $\mathrm{PCa}$ via the SOCS3 pathway. Cell Physiol Biochem 33: 195-204, 2014.

35. Gong H, Guo P, Zhai Y, Zhou J, Uppal H, Jarzynka MJ, Song WC Cheng SY and Xie W: Estrogen deprivation and inhibition of breast cancer growth in vivo through activation of the orphan nuclear receptor liver X receptor. Mol Endocrinol 21: 1781-1790, 2007.

36. Vedin LL, Lewandowski SA, Parini P, Gustafsson JA and Steffensen KR: The oxysterol receptor LXR inhibits proliferation of human breast cancer cells. Carcinogenesis 30: 575-579, 2009.

37. Chuu CP and Lin HP: Antiproliferative effect of LXR agonists T0901317 and 22(R)-hydroxycholesterol on multiple human cancer cell lines. Anticancer Res 30: 3643-3648, 2010.

38. El Roz A, Bard JM, Huvelin JM and Nazih H: LXR agonists and ABCG1-dependent cholesterol efflux in MCF-7 breast cancer cells: Relation to proliferation and apoptosis. Anticancer Res 32: 3007-3013, 2012

39. Nguyen-Vu T, Vedin LL, Liu K, Jonsson P, Lin JZ, Candelaria NR, Candelaria LP, Addanki S, Williams C, Gustafsson JA, et al: Liver $\mathrm{x}$ receptor ligands disrupt breast cancer cell proliferation through an E2F-mediated mechanism. Breast Cancer Res 15: $\mathrm{R} 51,2013$

40. Candelaria NR, Addanki S, Zheng J, Nguyen-Vu T, Karaboga H, Dey P, Gabbi C, Vedin LL, Liu K, Wu W, et al: Antiproliferative effects and mechanisms of liver $\mathrm{X}$ receptor ligands in pancreatic ductal adenocarcinoma cells. PLoS One 9: e106289, 2014

41. Wang F, Stappenbeck F, Matsui W and Parhami F: Inhibition of pancreatic cancer cell-induced paracrine hedgehog signaling by liver X receptor agonists and Oxy16, a naturally occurring oxysterol. J Cell Biochem 118: 499-509, 2017.

42. Joseph SB, Bradley MN, Castrillo A, Bruhn KW, Mak PA, Pei L, Hogenesch J, O'connell RM, Cheng G, Saez E, et al: LXR-dependent gene expression is important for macrophage survival and the innate immune response. Cell 119: 299-309, 2004.

43. Joseph SB, Castrillo A, Laffitte BA, Mangelsdorf DJ and Tontonoz P: Reciprocal regulation of inflammation and lipid metabolism by liver X receptors. Nat Med 9: 213-219, 2003.

44. A-Gonzalez N, Bensinger SJ, Hong C, Beceiro S, Bradley MN, Zelcer N, Deniz J, Ramirez C, Díaz M, Gallardo G, et al: Apoptotic cells promote their own clearance and immune tolerance through activation of the nuclear receptor LXR. Immunity 31: 245-258, 2009. 
45. Bensinger SJ, Bradley MN, Joseph SB, Zelcer N, Janssen EM Hausner MA, Shih R, Parks JS, Edwards PA, Jamieson BD and Tontonoz P: LXR signaling couples sterol metabolism to proliferation in the acquired immune response. Cell 134: 97-111, 2008.

46. Wang Q, Ma X, Chen Y, Zhang L, Jiang M, Li X, Xiang R, Miao R, Hajjar DP, Duan Y and Han J: Identification of interferon- $\gamma$ as a new molecular target of liver X receptor. Biochem J 459: 345-354, 2014

47. Wang Q, Sun L, Yang X, Ma X,Li Q, Chen Y, Liu Y,Zhang D, Li X, Xiang R, et al: Activation of liver X receptor inhibits the development of pulmonary carcinomas induced by 3-methylcholanthrene and butylated hydroxytoluene in BALB/c mice. Sci Rep 6: 27295, 2016.

48. Cui G, Qin X, Wu L, Zhang Y, Sheng X, Yu Q, Sheng H, Xi B, Zhang JZ and Zang YQ: Liver X receptor (LXR) mediates negative regulation of mouse and human Th17 differentiation. J Clin Invest 121: 658-670, 2011.

49. Villablanca EJ, Raccosta L, Zhou D, Fontana R, Maggioni D, Negro A, Sanvito F, Ponzoni M, Valentinis B, Bregni M, et al: Tumor-mediated liver $\mathrm{X}$ receptor-alpha activation inhibits $\mathrm{CC}$ chemokine receptor-7 expression on dendritic cells and dampens antitumor responses. Nat Med 16: 98-105, 2010.
50. Feig JE, Pineda-Torra I, Sanson M, Bradley MN, Vengrenyuk Y, Bogunovic D, Gautier EL, Rubinstein D, Hong C, Liu J, et al: LXR promotes the maximal egress of monocyte-derived cells from mouse aortic plaques during atherosclerosis regression. J Clin Invest 120: 4415-4424, 2010.

51. Noghero A, Perino A, Seano G, Saglio E, Lo Sasso G, Veglio F, Primo L, Hirsch E, Bussolino F and Morello F: Liver X receptor activation reduces angiogenesis by impairing lipid raft localization and signaling of vascular endothelial growth factor receptor-2. Arterioscler Thromb Vasc Biol 32: 2280-2288, 2012.

52. Pencheva N, Buss CG, Posada J, Merghoub T and Tavazoie SF: Broad-spectrum therapeutic suppression of metastatic melanoma through nuclear hormone receptor activation. Cell 156: 986-1001, 2014. 